Pollard, A. (2008) Knowledge transformation and impact: aspirations and experiences from TLRP, Cambridge Journal of Education - Special Issue, $38(1), 5-22$.

\title{
KNOWLEDGE TRANSFORMATION AND IMPACT: ASPRIATIONS AND EXPERIENCES FROM TLRP
}

\author{
Andrew Pollard \\ Director, Teaching and Learning Research Programme, \\ University of London \\ a.pollard@ioe.ac.uk
}

\begin{abstract}
This paper reviews the intentions and strategies adopted by the UK's Teaching and Learning Research Programme (TLRP) in its attempts to maximise the impact of its research portfolio. The Programme's early commitment to user engagement and to an 'interactive, iterative, constructive, distributed and transformative' impact strategy is described. The specific outputs and initiatives of the Programme are analysed in relation to three issues - the transformation of findings beyond abstract academic forms; the authentic engagement of users; and the exploitation of ideas which are culturally and politically current. From TLRP experience, it is argued that such work requires significant resources, technology, imagination, expertise and time. The paper concludes with a call for substantial, long-term investment in an appropriate infrastructure to maximise the impact of research in education.
\end{abstract}

\section{Introduction}

The UK's Teaching and Learning Research Programme is a strange beast, with some projects which started in 2000 and others which will not begin until 2008. Whilst some ended in 2003 , others may continue until 2012 . The total number of projects is likely to exceed 70 , and these are complemented by some 20 cross-Programme thematic analyses of various sorts. Projects cover issues ranging across the entire lifecourse in many educational sectors and involve research teams from all parts of the UK.

And yet, despite its affinity with a camel designed by committee, this Programme is a fantastic opportunity. At over $£ 40 \mathrm{~m}$, it is the biggest initiative of coordinated research that UK education has ever known and the largest investment in ESRC's portfolio. Over half of the funding has come from England's higher education funding council (HEFCE), whose Chief Executive in the late 1990s, Brian Fender, had the foresight and commitment to invest in educational research at a time when it was perceived to be in a relatively weak state.

HEFCE, together with ESRC and contributions from other UK governments and, latterly, EPSRC, made it possible for education to tackle two major issues.

- To contribute to new knowledge on teaching and learning

- To improve the quality of educational research in the UK

This paper is not about either objective directly, but rather focuses on the strategies which have been developed to try to maximise the impact of the findings emerging from TLRP's projects and of various synoptic attempts to summarise these. 
Written in the Spring and Autumn of 2007, the story is far from over. And yet it is an appropriate moment to take stock because investment in the infrastructure of TLRP is scheduled to scale down at the end of 2008. It is crucial therefore, that the strategies being developed and implemented are used to maximal effect in the time available.

As an exceptional opportunity, the experience of TLRP may also be a useful case study for others who wrestle with the challenges and dilemmas of how to maximise the impact of research. And there is also the key question of whether the UK needs an infrastructure to make high quality evidence more easily available to practitioners and policy-makers. This account, which acknowledges as many problems as successes, is offered as a contribution to such deliberations.

\section{Strategic foundations}

The first two years of TLRP's work were led by Charles Desforges and John Kanefsky. They, with expert guidance from the perceptive Steering Committee of the time, provided a very strong foundation for the Programme's future knowledge transfer activities. Three particular aspects of this might be identified.

First, there was an explicit commitment across the entire Programme to 'user engagement'. Indeed, a decision had been taken to foreground 'user engagement' in all commissioning processes. It was thus introduced as a criterion for assessing applications and all bids were required to set out their specific 'Communication and Impact Plan'. A very wide range of UK bodies had been consulted during the process of establishing the Programme and the first phases of commissioning. Additionally however, a more systematic 'Communication Audit' was carried out to identify potential beneficiaries and existing networks of communication and influence. This produced some formidable lists of organisations in each sector and showed the enormous scale and complexity of the field.

Second, there was a careful review of what was known about knowledge transfer and impact. John Kanefsky, who held the particular brief for communication and impact, was particularly influenced by research on the diffusion of innovation. His paper of August 2001 drew on Rogers' classic work on the subject (1995). As Kanefsky summarised:

The spread of ideas, innovations and technologies can be analysed under a common basic framework involving four elements:

- An idea or innovation (not necessarily novel);

- Channels of communication to spread knowledge of it;

- Time during which diffusion takes place (important but often ignored);

- A social system in which this occurs, with a group of potential 'adopters'.

Crucially, the analysis sees diffusion not as an inevitable, linear phenomenon as had been assumed in early writing on the subject. Rather it postulates a convergence model, where the take up of new ideas is a shared process between innovators and adopters. It also recognises that new ideas are often ignored, rejected or discontinued after adoption, or only taken up by a very small part of their potential 'market'. They are also frequently modified significantly as part of the innovation and adoption process' (2001:1)

Taking this further, Desforges and Kanefsky developed close links with Sandra Nutley and her colleagues from the Research Unit for Research Utilisation at St Andrews, part of ESRC's Network for Evidence-based Policy and Practice. RURU was working towards an analytic 
framework for understanding how evidence could be transformed into practice, and offered to clarify terminology and 'map the terrain' (Nutley, Walter and Davies, 2002). The latter linked evidence-base practice to types of knowledge, institutional contexts, conceptual frameworks, models of process and implementation of interventions. Consideration of this framework and examples from the Joseph Rowntree Foundation, Cabinet Office and Cochrane Collaboration demonstrated that 'achieving impact is a complex and multifaceted process' and that there was much still to learn about it.

User engagement and ideas on knowledge transfer were brought together in a 2002 group of seminars entitled 'TLRP Strategies for Impact'. These affirmed the commitment - and were almost the last activities organised by the initial TLRP Directors' Team. However, the latter bequeathed a formal 'Communication and Impact Plan' (TLRP 2001) - which we can take as the third element of the strategic foundation of TLRP's approach.

TLRP's Communication and Impact Plan begins strongly with a clear definition of impact which was grounded in the reviews which had taken place.

We conceive impact not as a simple linear flow (of research followed by transformation, dissemination of findings and adoption), but as a much more collaborative process: interactive, iterative, constructive, distributed and transformative. ... For us, impact therefore includes increasing awareness of new ideas and openness to change as well as direct influence on practice and policy. Working for impact is embedded in everything we do (emphasis in original). (TLRP 2001, 1)

This statement clearly reflects the influence of both Rogers and Nutley, but also the commitment to collaborative user engagement. The document went on to set out seven components of the TLRP strategy:

- Working with networks of practitioners, learners and others;

- Engaging with a wide range of user organisations and other stakeholders;

- Contributing to strategic debates about teaching and learning;

- Raising the profile of evidence-informed teaching and learning;

- Communicating conceptual, methodological and practical ideas;

- Supporting capacity building activities, including knowledge transformation;

- Facilitating discussion within the Programme on transformation and impact.

So far, so good, one might say. However, just as Nutley's 2002 work was insightful, promising, but incomplete (see Nutley, Walter \& Davies, 2007), so the TLRP approach was much stronger on intention than it was on realisation.

\section{Developing an output portfolio}

When Andrew Pollard became TLRP Director in April 2002, there appeared to be two priorities in this area of work. First, some researchers within the Programme felt that they had not been greatly involved in the development of the Communication and Impact Strategy and needed to be engaged. Second, there was a pressing need to create and manage specific outputs for those projects which were then starting to move towards their conclusion - for, above all, impact always depends on the quality and significance of the research itself. As findings became available then, how could the impact strategy be put into practice? 
A Thematic Group entitled the Publications and Other Outputs Group (POOG) was rapidly formed with influential researchers and users. Convened by myself, it included Catrin Roberts (Nuffield Foundation), Anne Diack (Innovation Unit), Lesley Saunders (General Teaching Council, England), Dai Hounsell (Enhancing Teaching \& Learning Project) and Martin Ince (ESRC Media Fellow). In a series of meetings, the group discussed the issues and worked on how the strategic direction already established could be implemented. The many contributions made in these deliberations were integrated and applied in a 'TLRP Output Review’ (TLRP 2002, see: http://www.tlrp.org/manage/admin/outputreview.html).

The Output Review attempted to specify clear expectations from projects and the forms of support which would be provided by the Programme as a whole.

Potential outputs were reviewed and categorised in terms of the stage during each project when the output was most likely to be used, the main audience for the type of output and the form of the output. Additionally, the identification of 'key findings' was highlighted as a crucial focus. This was represented in tabular form (see below).

\begin{tabular}{|c|c|c|c|c|}
\hline \multirow{5}{*}{$\begin{array}{l}\text { 'Public and User } \\
\text { audiences' }\end{array}$} & \multicolumn{4}{|c|}{$\begin{array}{l}\text { The 'conducting research' stage } \\
\text { Forms of project output }\end{array}$} \\
\hline & Electronic & Paper & Events & Media \\
\hline & $\begin{array}{l}\text { 1a Regard } \\
\text { registration }\end{array}$ & $\begin{array}{l}\text { 2a Project } \\
\text { newsletters }\end{array}$ & & \\
\hline & $\begin{array}{l}\text { 1b CERUK } \\
\text { registration }\end{array}$ & $\begin{array}{l}\text { 2b Articles in } \\
\text { popular outlets }\end{array}$ & $\begin{array}{l}\text { 3a User } \\
\text { engagement } \\
\text { events }\end{array}$ & $\begin{array}{l}\text { 4a Reactive } \\
\text { press strategies }\end{array}$ \\
\hline & $\begin{array}{l}\text { 1c Gateway web } \\
\text { page }\end{array}$ & $\begin{array}{l}\text { 2c Articles in } \\
\text { professional outlets }\end{array}$ & $\begin{array}{l}\text { 3b Advisory } \\
\text { Group events }\end{array}$ & $\begin{array}{l}4 b \text { Media } \\
\text { training }\end{array}$ \\
\hline \multirow{3}{*}{$\begin{array}{l}\text { Academic } \\
\text { and } \\
\text { 'technical } \\
\text { audiences }\end{array}$} & $\begin{array}{l}\text { 5a Project } \\
\text { website }\end{array}$ & & $\begin{array}{l}\text { 7a Inter-project } \\
\text { activities }\end{array}$ & \\
\hline & $\begin{array}{l}\text { 5b Website } \\
\text { working papers }\end{array}$ & $\begin{array}{l}\text { 6a Conference and } \\
\text { working papers }\end{array}$ & $\begin{array}{l}\text { 7b Thematic } \\
\text { Group activities }\end{array}$ & \\
\hline & $\begin{array}{l}5 c \text { British } \\
\text { Education Index }\end{array}$ & & $\begin{array}{l}\text { 7c Systematic } \\
\text { reviews }\end{array}$ & \\
\hline
\end{tabular}

\begin{tabular}{|c|c|c|c|c|}
\hline \multirow[t]{5}{*}{$\begin{array}{l}\text { Public and } \\
\text { User } \\
\text { Audiences }\end{array}$} & \multicolumn{4}{|c|}{$\begin{array}{l}\text { The 'sharing knowledge' stage } \\
\text { Forms of project output }\end{array}$} \\
\hline & Electronic & Paper & Events & Media \\
\hline & Key findings & Key findings & Key findings & 11a Key findings \\
\hline & $\begin{array}{l}\text { 8a User e- } \\
\text { dissemination }\end{array}$ & $\begin{array}{l}\text { 9a User } \\
\text { dissemination }\end{array}$ & 10a User events & $\begin{array}{l}\text { 11b User } \\
\text { championing }\end{array}$ \\
\hline & & $\begin{array}{l}\text { 9b Teaching } \\
\text { materials }\end{array}$ & $\begin{array}{l}\text { 10b Cultural } \\
\text { innovation } \\
\text { (drama/art) }\end{array}$ & $\begin{array}{l}\text { 11c Pro-active } \\
\text { press strategies }\end{array}$ \\
\hline
\end{tabular}




\begin{tabular}{|c|c|c|c|c|}
\hline & $\begin{array}{l}\text { 8b Multimedia } \\
\text { presentation clips }\end{array}$ & $\begin{array}{l}\text { 9c } \\
\text { Teacher training } \\
\text { materials }\end{array}$ & $\begin{array}{l}\text { 10c Policy } \\
\text { discussion and } \\
\text { commentary }\end{array}$ & 11d Press releases \\
\hline & $\begin{array}{l}8 \mathrm{c} \text { Discussion } \\
\text { forums }\end{array}$ & 9d Briefings & $\begin{array}{l}\text { 10d Scenario } \\
\text { planning }\end{array}$ & $\begin{array}{l}\text { 11e Press } \\
\text { interviews }\end{array}$ \\
\hline & $\begin{array}{l}\text { 8d e-Improving } \\
\text { learning books }\end{array}$ & $\begin{array}{l}\text { 9e Improving } \\
\text { Learning books }\end{array}$ & $\begin{array}{l}\text { 10e Consensus } \\
\text { conferences }\end{array}$ & \\
\hline & & 9f Pamphlets & & \\
\hline \multirow{3}{*}{$\begin{array}{l}\text { Academic } \\
\text { and } \\
\text { Technical } \\
\text { audiences }\end{array}$} & & $\begin{array}{l}\text { 13a Journal } \\
\text { papers }\end{array}$ & $\begin{array}{l}\text { 14a Academic } \\
\text { conferences }\end{array}$ & \\
\hline & 12a e-books & $\begin{array}{l}\text { 13b Academic \& } \\
\text { technical books }\end{array}$ & & \\
\hline & & $\begin{array}{l}13 c \text { Final report to } \\
\text { ESRC }\end{array}$ & & \\
\hline
\end{tabular}

Textual explication was offered in relation to each cell and, in due course, this framework developed a web presence as the 'TLRP Outputs Portfolio' offering detailed guidance on each major output (http://www.tlrp.org/manage/admin/outputnew.html). The Programme's expectations of projects were also set out:

Project teams will of course devise their own engagement and impact strategies. However, within the overall provision, the Programme expects the following to be normally included. As appropriate, direct support in achieving this will be provided.

- 'Gateway web pages'

- Appropriate user representation on Advisory Groups

- Media training of a nominated spokesperson

- $\quad$ Project website

- $\quad$ Use of the British Education Index

- Identifying 'key findings'

- Cross-Programme user events

- $\quad$ Pro-active press strategies

- $\quad$ 'Briefings' for policy makers and others

- $\quad$ 'Improving Learning books' through Routledge

- Journal papers through Routledge

- Participation in targeted academic conferences

Annual reports to the TLRP Steering Committee provided an opportunity for projects to clarify progress towards these expectations. In due course, planning sessions - termed 'Output Summit Meetings' to emphasis their importance - were also scheduled a year from the completion of each project to provide a focal occasion for taking stock of progress, finalising an appropriate impact strategy and coordinating the efforts of the Project Team with TLRP's Associate Director, Media Fellow and Office Staff.

\section{Learning through the Directors' Team}

At the same time as the Output Portfolio and expectations of projects was being developed, a pattern of work for the post-2002 Directors' Team was established. The team had been set up to ensure coverage of every major sector in which research was being commissioned - 
schools, further, higher and professional education and workplace and lifelong learning. The size of the team varied over the period but, apart from the full time Director, was comprised of between two and four part-time appointments for, in the main, two days per week. Colleagues at various times included Steve Baron, Alan Brown, Miriam David, Kathryn Ecclestone, Mary James, John Siraj-Blatchford and Richard Noss.

Members of the team had many responsibilities of which two were particularly prominent. First, they were required to liaise closely with a group of projects in their sector - and to act as 'critical friends' to them. Second, of particular importance to us here, they were charged with developing relationships with national organisations which had particularly 'high leverage' in relation to their sector or specialist field. To make this work, the early Communication Audit was revisited and updated. Decisions were then made to identify key bodies for personal engagement and participation, others to be kept informed though publications and a third group of organisations which, it was felt, were regrettably beyond the reach of our available resources. An indication of bodies in the first two groups is available at: http://www.tlrp.org/users/national_orgs.html.

In the contacts which were developed with high leverage national bodies, TLRP experienced almost totally consistent support at the highest levels. Given the prominence of the rhetoric of 'evidence-based policy and practice' and the quality assurance of ESRC, chief executives were almost always welcoming and keen, in principle, that the outcomes of research should inform the policies and practices of their organisations. A good deal of information was exchanged and attempts made to find appropriate alignments of interest - as TLRP's extensive files and the regular reports from the Directors' Team attest. Relationships then tended to form with a new set of colleagues at more specific operational levels and everything then depended on the relevance and scheduling of research projects.

There were patterns in this. If there was a match of user priorities and research findings, then things happened - as, for instance, with Jean Rudduck's work on pupil voice at the DfES or take up by the Qualifications and Curriculum Authority?? of science education findings. If not, then goodwill tended to be expressed but not much more. Of course, those in user organisations were in rather different parts of the education system and their perception of issues was not normally from a research perspective. However, it was also apparent that, in most user organisations, highly committed staff had impressive expertise in terms of implementation issues in the context of political and practical processes. Reciprocal respect grew, despite the differences in responsibilities and circumstances. The experience of meeting such large numbers of colleagues reinforced the stance which had been emerging in the thinking of the Directors' Team and is reflected in the 2005 Education Review Annual Lecture given by the Director (Pollard 2005). It was argued that not only is it impossible for education as a form of social science to offer categoric 'what works' answers (though degrees of confidence should be made transparent in a warrant), but it is also inappropriate in the complex democratic system of the contemporary world to make such claims. Research-based understanding, in other words, must take its place in the discursive spaces of modern society in which appropriate action is debated and resolved. Again, the non-linear, interactive and iterative nature of the communication and impact process was affirmed.

\section{Towards a user-centric model of dissemination and impact}

ESRC procedures required the Directors' Team to report annually on impact activities and data on this was collected from projects. Of course, tracing a causal link between research activity and changes in policy and practice is fraught with difficulty - and there is by no means agreement on how this should best be done or on what timescale. A 1999 report to ESRC by Ben Martin and colleagues (Assessing Research Impact on Non-Academic Audiences) had concluded that the most appropriate strategy was to conduct telephone 
interviews with a carefully selected sample or users one or two years after the conclusion of each project, and to incorporate the resulting data into an overall programme evaluation. It was necessary to trace 'networks and flows' and also 'post-research activities' and to involve both users and researchers in the evaluation as an integral part of the other programme implementation and evaluation work. In reflecting on these recommendations however, they identified real difficulties in tracing users and researchers over time and in documenting specific evidence of tangible influence. The trail from research to application is undoubtedly hard to trace.

The experience with user organisations and reflection on the challenges of tracing impact caused TLRP to revisit the extent to which user-engagement could be built upon. Was there a better way of working for impact?

In the early days of POOG, Dai Hounsell had drawn attention to an Australian report on impact and how to understand it (Figgis et al, 2000). Commissioned by the Department of Education, Training and Youth Affairs (DETYA) the analysis rejected the common strategy of attempting to track research findings as they filtered through to policy and practice - as exemplified by Martin's report of 1999. Rather, they experimented with starting from the other end, the adoption of a policy, and recommended 'backtracking' to determine in what way, if at all, research influence had been exercised.

This approach is founded on understanding the perspective of the practitioner and policymaker - as well as the research knowledge available. It acknowledges however, a significant gap between these which needs to be filled. Three questions then follow:

1. How, they ask, can research knowledge be 'propelled out of its abstract conceptual space' so that users can decide on its value?

2. What, they posit, is needed to energise practitioners and policy-makers to cross this gap and to 'seek new knowledge beyond the demands of their daily work'?

3. And how too should the broader flow of contemporary ideas, providing the context for this activity, be represented?

Figure 2 below, is the model which Figgis et al offered in response to these questions. [?? figure to adjust!]

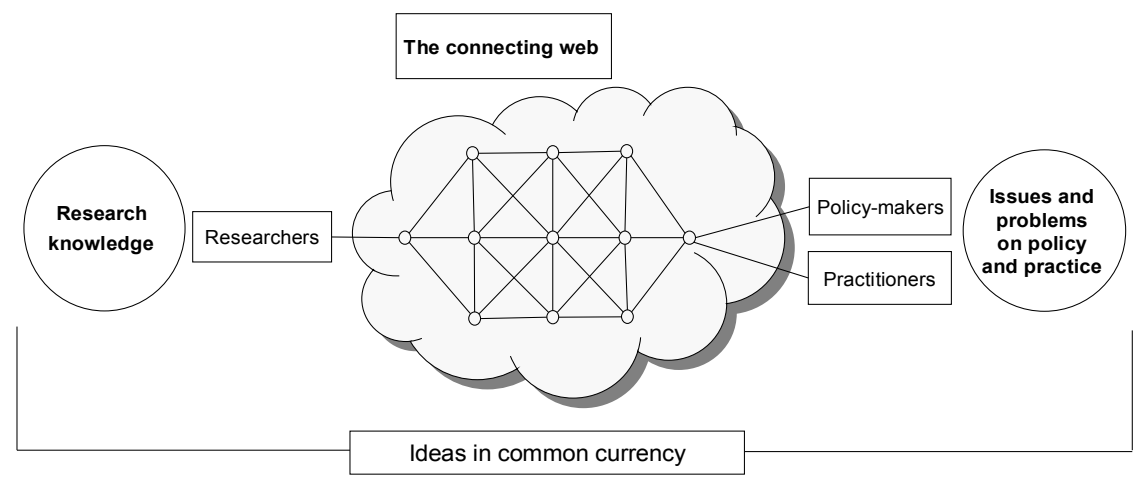


Here, we see research knowledge is embodied by 'researchers', and professional problems by 'practitioners' and 'policy-makers' - the point being that personal relationships between key representatives of such groups are crucial to the interchange. Then we have what Figgis et al called the 'connecting web' - the specific mechanisms which bring people together to exchange and develop knowledge and understanding. In a sense, the latter is best described as a form of learning space, with each node constituting an activity. Permeating all of this, are 'ideas in common currency' which provide a contextual backdrop for the activity.

This model is founded on respect for different roles. It does not privilege one form of knowledge or expertise over another. As Figgis et al stated:

To talk about impact of educational research is a gross distortion of the situation in that it implies that research is the sole active agent. In fact, practitioners and policymakers are equally (or more) active in creating 'impact'. The word 'impact' might best be abandoned as a misguided relationship of the relationship between educators and research. (2000, p 356)

In summary, as the Programme matured, more and more thought went into the relationship between user organisations and the research community and to the steps which might be taken to engage constructively in the 'connecting web'. The most elaborated expression of this work came from a Thematic Seminar Series on user engagement coordinated on behalf of TLRP by Anne Edwards, Judy Sebba and Mark Rickinson (see Edwards, Sebba and Rickinson 2007). The series explored patterns in the experiences of projects which had been engaging closely with users and identified an 'emerging reciprocity where the public understand(s) how science works but equally science understands how its publics work' (2007: 647).

The coordination of activities had nevertheless been challenging. In part, this was because of the variable scheduling of projects in key sectors and differences in the priorities of research teams which resulted in a more fragmented flow of outputs than would be ideal. In part, the processing of publications in journal and book production systems has caused delays in some cases. Further, the complexity of the TLRP, with successive new phases being commissioned just as other phases are completing has certainly strained the limited resources of the Programme Team. Even now, as I write in the Autumn of 2007, it remains possible that opportunities for user-centric impact will be lost in the later stages of the Programme because of a lack of funding at the time when such investment would be most effective - though strenuous efforts are being made to avoid this situation.

Notwithstanding such problems, in a second wave of Programme initiatives, TLRP has made many attempts to explore across the 'connecting web'. The next sections rehearse some of these and are structured around the major issues raised by Figgis.

- the outputs of projects - which links to Figgis et al's question on how research knowledge can be 'propelled out of its abstract conceptual space' so that users can engage with it. How to 'transform' knowledge?

- relationships with users - addressing Figgis et al's question on how to energise practitioners and policy-makers to cross the research - application gap and to 'seek new knowledge beyond the demands of their daily work'? How to engage the practice of users?

- the contemporary context - how to exploit Figgis et al's 'ideas in common currency'? 


\section{Transforming outputs 'beyond the abstract'}

In the section below, five areas of work are reviewed in which TLRP has attempted to provide outputs in ways which are 'transformed' for a range of audiences - with particular attention to policy makers and practitioners.

\section{Publications}

TLRP does, of course, have a very full range of publications ranging from the conventionally academic to those intended for busy policy makers, practitioners and students. The Programme's DSpace electronic repository is climbing towards 1000 entries, all tagged and searchable from the website. There are specialist academic books and sophisticated project websites some of which contain instruments and methodological information. Papers and special issues in Routledge education journals are now considerable in number, with particular groups from Education Review and Research Papers in Education. In more accessible form are the books which most projects have in the Improving Learning or Improving Practice series, also published by Routledge. Providing the most concise form of summary are the Research Briefings from each project and the Outcome Posters which are being developed for use at events. TLRP is also negotiating with SAGE to publish a short series of International Handbooks on teaching and learning in particular sectors, thus situating major TLRP findings within an overview of cutting edge knowledge in the field.

\section{The TLRP website}

The internet is now the major means of information exchange, particularly for students and researchers but also for practitioners and policy-makers. The TLRP website has been under constant development since its initial creation at Exeter. In 2002 it was redesigned by a Cambridge team based at CARET (the Centre for Applied Research in Education Technology). Colleagues from CARET bridge the researcher-technology divide and have been hugely responsive to the needs of the Programme over the years. Thus, in addition to the various tools for internal communication, we have the capability to post new news and features in minutes and offer RSS feeds to other websites. Most significantly in relation to engaging with user visitors, we are able to greet unique audiences - students, practitioners, policy-makers, journalists, researchers - and guide them to particular parts of the site which are likely to be most suitable for their needs. This is only possible because of the underlying an electronic repository enables each output to be classified by topic and form. Thus, for instance, various forms of 'user summary' can be made available, whilst more advanced searches will pick up more sophisticated material. The interface of TLRP data with other resources has been developing strongly. Appropriate publications have been fed to BEI for some years, and this has now been established for ESRC Society Today and for the new Evidence for Education Portal (EEP).

\section{Commentaries}

A common problem with research is that findings become available only when nobody cares anymore. We wanted to find a way to bring the expertise of the research community to bear quickly on contemporary issues. TLRP thus selected a small number of major issues of public interest and sponsored small groups of researchers and users to meet and produce a research-informed contribution to the debate. Among the titles produced or in production are those on: Personalised Learning, 14-19 Education, Science Education, Teaching and Learning in Schools, Neuroscience and Education and Apprenticeship. Where possible, these documents have been produced with partners, 'launched' with as much profile as possible and followed through with practical discussion. Attractively designed and presented, they have been a major focus for downloads from the TLRP website, with two having been downloaded over 100,000 times. For more information, see: www.tlrp.org/pub/commentaries.html . 


\section{Journalism}

A very welcome form of support from ESRC has been the assignment of a 'Media Fellow' to the Programme for the nominal period of some 30 days per year. Martin Ince has provided both strategic advice as well as hands on support of many sorts. Additionally, as the Programme moves forward, we have also been able to draw on other journalists from time to time. Thus David Budge, Diane Hofkins and Ian Nash have all supported dissemination activity. Of course, among the project directors there have been many with considerable media experience too. Two were regular newspaper columnists and many had deep links to education authorities, teacher associations, government agencies, educational institutions, etc. The potential was thus very strong. Media training was nevertheless offered to a representative from every project and this not only support the development of skills but also provided a form of team-building exercise for the idea of communicating findings from TLRP. Having made such provision, we have found that research findings on teaching and learning tend to lack the scandal, controversy and conflict which would propel material to the top of the news in public media. Further, attempts to contribute to breaking news stories have been repeatedly frustrated by a contractual requirement to give key funders 24 hours notice of TLRP press releases - though there has been no interference whatsoever. It should also be acknowledged that our stance of trying to work in collaboration with practitioners and policymakers has meant that we have tended to avoid public conflict in favour of frank back-stage discussion. We nevertheless have had a number of important news stories - for instance on the use of technologically-based toys by young children, on learning how to learn, the effectiveness of group work and on apprenticeships. The overarching messages of TLRP, for instance, offering an authentic analysis of lifelong learning or presenting evidence that routine practices of teaching and learning are more significant than structural reform of school systems, are stories which remain to be fully communicated in the media.

\section{The Teacher's Guide to TLRP and the Principles into Practice DVD}

TLRP has attempted to synthesise the results from schools projects, the first group to complete, and to represent them to all schools. Building on a series of Newsletters which were distributed to UK schools in the first four years of the Programme, a Teacher's Guide has been produced together with a supplementary DVD showcasing examples of classroom practice. Presented in a colour magazine form, the key conceptual carrier for these materials is the argument that evidence-informed 'educational principles' can be identified and then applied through the use of professional judgement and expertise. With additional financial support from ESRC, DfES and the Welsh Assembly Government, 30,000 copies have been distributed to every UK school and represent the most significant attempt yet made by TLRP to communicate to practitioners in a direct, accessible and comprehensive way. At the same time as this material went out, some 500 selected UK opinion leaders were sent copies of all school-focused Research Briefings and media coverage is being sought. Whilst this illustrates the use of a new technology by the Programme, complementary innovation has come from the Home-School Knowledge Exchange project which has developed a drama to illustrate key findings on transfer issues. Again, a DVD will be issued in conjunction with a Research Briefing in an attempt to maximise awareness of this important finding on the benefits of involving parents in primary-secondary transfer.

\section{Engaging the practice of users}

Engaging practitioners and policy-makers across Figgis's 'connecting web' was undoubtedly a major challenge faced by TLRP. Some projects achieved this particularly successfully when they worked within and helped to create networks of influence and action. For example, Jean Rudduck's pupil consultation project both promoted networks of teachers and was taken up by NCSL's infrastructure and then drawn to the centre of DfES policy on personalisation. Lorna Unwin and Alison Fuller's work on learning environments and apprenticeship has 'taken off' in somewhat similar ways in relation to workplace learning. Anne Edwards and 
Harry Daniels have seen a tremendous interest from public service providers for their work on inter-professionalism. Such cases are characterised by user engagement which is authentic and research which is both of high relevance and quality.

At a Programme level, work has also gone on to engage users in ways judged most likely to support adoption of research findings and analyses for practice and policy. Four examples are offered below.

\section{Practitioner applications}

The transformation of abstract research findings into practical activities suitable for classroom application is a major challenge. TLRP's 'practitioner applications' (www.tlrp.org/search/pa) offer such research tasters for school teachers based on the findings of some 20 school sector projects. The preparation of these activities was carried out by CUREE (Centre for the Utilisation of Research Evidence in Education) but the format has been tried and tested in successive editions of Andrew Pollard's textbooks on Reflective Teaching. Indeed, the activities are embedded in the structure of that work and will be sustained through it into the future. In this way, TLRP findings are being made available in a form which may be particularly suitable for initial teacher education and continuous professional development activity. The contemporary development of Masters Level Post-Graduate Certificates of Education is providing a high potential demand for such resources, on which the London Institute of Education's primary education team is leading.

\section{Public reviews}

These are important opportunities because the very existence of a 'review' denotes a decision by the sponsoring body to 'open up' and rethink their policy or provision. Sometimes, as with the Nuffield 14-19 Review (led from Oxford) and Esmee Fairbairn Primary Education Review (led from Cambridge), the initiative comes from outside government and represents a mustering of evidence in an attempt to influence policy. On other occasions, as in the activities of the House of Commons Select Committee, the DfES Gilbert Review, the TDA consultation on Teacher Workforce Standards, the Treasury Budgetary Review or Conservative Party Policy Review Groups, the connection to the levers of change is, ostensibly, more direct. Wherever possible, TLRP has tried to contribute to such initiatives, regarding them as very clear opportunities to offer new thinking. Sometimes, the available evidence has been weak or unavailable at the required time and on other occasions TLRP has lacked the resources to follow though. However, some extremely valuable interchanges have taken place with key players within important organisations over many years. As TLRP's findings accumulate, are better represented by Research Briefings and books and are summarised more effectively through thematic analysis, Commentaries and reflection, we have found that the opportunities presented by reviews can be exploited more comprehensively.

\section{Placement fellowships}

Following two appointments of academics within the Scottish Government, negotiations are underway in Northern Ireland and Wales to establish TLRP placement fellowships in their government education departments. This initiative draws on an ESRC scheme which cofunds a proportional appointment to explicitly bridge the research - policy space. As TLRP findings become available, this becomes an increasingly valuable opportunity and should enable a tight focus on the transformation of available findings for policy priorities.

\section{Events}

All TLRP projects run events with users. In most cases, these stem from the beginning of the work and are often sustained through advisory groups, newsletters and other meetings. At the end of projects, more prominent and larger events tend to be held to launch findings and publications and to provide a springboard for follow up activities. At a Programme level, events with users are also increasingly important. For example, in 2006 the Director and 
Deputy Director spoke at the conference of National Teacher Research Panel in England and the Director led an event to launch a new Pedagogy Campaign in Wales. The Programme's Annual Conference held in Glasgow drew some 40 Scottish policy-makers and a day of the event was entirely structured around their priority themes of 'learning', 'equity' and 'transitions'. Major events for November 2008 are being planned for Westminster policy makers and others will be held in Cardiff, Edinburgh, Belfast and the English regions. Some events take a particular focus where the Programme has a particularly strong cluster of projects - for instance, on workplace learning or widening participation in higher education.

Such initiatives make a contribution by raising awareness, but TLRP experience is that there is no substitute for direct relational engagement with users. The focus thus, moves to the question of scaling up and social transformation. This may be achieved more easily by exploiting the third of Figgis et al's challenges - how to exploit 'ideas in common currency'.

\section{Exploiting 'ideas in common currency'}

Figgis et al helpfully highlight what they call: 'the crucial bed of ideas in common currency which envelop everyone' (2000, p343) and the TLRP strategy has certainly attempted to exploit the opportunities to enhance the impact of project findings which the context of the time has afforded. Six of these might be identified:

1. The commitment of the Labour governments in each part of the UK since 1997 to the improvement of public services has coincided with the development of the Programme and provided a beneficial strategic alignment at the level of fundamental goals. TLRP's goal of using research to: 'improve learning outcomes for learners', reflected and contributed to the spirit of the times.

2. Further, the contemporary rhetoric of 'evidence-based policy and practice' has been perhaps the most favourable to TLRP and the field of educational research generally. Convening a 2005 London conference for OECD's CERI, TLRP was able to support the gradual qualification of this aspiration towards the more realistic and appropriate notion of 'evidence-informed policy and practice', and this too has provided the Programme with a legitimating rationale in approaching governments, their agencies and others.

3. At a later point, when initial improvements brought about by national strategies began to level off and the political pressure from international comparisons of TIMMS and PISA started to mount, the demand for evidence informed ideas grew considerably. The development of 'personalised learning' and the Gilbert Review, to which the Programme's projects contributed substantially, provided the strongest case of this.

4. TLRP has also benefited from the major policy reviews conducted by political parties which are out of power. One of the Programme's researchers chaired a review for the Liberal Democrats and the Deputy Director led a committee evaluating evidence for the Conservative's review of public service provision. Authentic and open discussions with senior politicians out of office have been found to be far easier to conduct than with Ministers, who tend to be buffered by their civil servants. The need to develop new policies to appeal to the electorate is something to which TLRP has consistently tried to contribute.

5. Devolution has also brought opportunities, offering comparative case studies of different approaches to issues of policy and practice. With policy makers and practitioners in each UK country tending to be absorbed in the detail of their own 
context, TLRP's UK-wide responsibility has given it a broader vision to share in discussion of effectiveness and possibilities.

6. In the next few years, towards the end of the Programme, it seems likely that TLRP will be able to work with the flow of evolving policy. One dimension of this is what we detect as a growing trend of political opinion away from over-prescriptive centralisation. One of TLRP's central findings on the significance of teacher learning and expertise as a precondition for pupil and student learning draws strength from such a trend. In higher education, a similar focusing on the development of pedagogy in a range of subject areas and on factors affecting widening participation also creates excellent opportunities. The crucial role of workplace learning in developing UK skills and economic growth seems well established. Further, an integrative dimension lies in the growing focus on new technologies in learning, on which TLRP has been able to secure new funding in excess of $£ 10 \mathrm{~m}$ to investigate from 2007 to 2012.

On the other hand of course, these 'ideas in common currency' may not actually be sufficient to bear the weight of the more radical TLRP implications. An education system which remains so strongly influenced by the Victorian era does, after all, have a long way to travel. Nevertheless, there are now many points of entry into constructive discussions on the appropriate education for the $21^{\text {st }}$ century.

However, we have to acknowledge that even this well resourced Programme has been extremely stretched to exploit such opportunities. In particular, the education system is so large, complex and fragmented that comprehensive coverage of it, even with sectoral specialisation, is impossible.

It is perhaps helpful to say a word about the infrastructure at this point. Within the TLRP Office, as the Programme grew in scale, it became possible to plan very tangible support for projects. Thus the full-time roles of managers for 'Events, Media and Engagement' and 'Office, Outputs and Communication' were created, followed by that of the part-time Website Manager and DSpace Researchers. The sector-focused Directors' Team each have their portfolio of projects with whom they liaise and the schedule of these has been set by the sequence of almost a dozen phases of funding and commissioning from 1999 to 2008. In these ways, TLRP has been able to introduce cost-effective systems to support the efforts of projects and has attempted to 'professionalise' the implementation of important parts of the overall communication and impact strategy - but the schedule and grouping of projects reflects a good deal of pragmatic rationalisation of decisions made beyond the control of the central team.

\section{Towards scaling up and transformation}

Scaling up is a crucial issue for public policy. Whilst all TLRP projects engage in some way with the improvement of learning outcomes, this may be in relation to a number of cases and in no project have findings been tested in terms of large-scale interventions at system level. On behalf of the DfES Innovation Unit, Philippa Cordingly and CUREE have recently worked on these issues (Cordingley, 2007) and begun to tease out a set of principles which need to be considered when scaling up. Issues under consideration include: a meaningful focus, commitment, collaboration, leadership, evaluation, evidence tools, strategic positioning, communication, regulation and monitoring. The key question is how the enthusiasm of 'early adopters' can be spread and institutionalised within the system as a whole.

Seen with panache and a sweep of history, David Hargreaves has speculated on how to stimulate radical, rather than incremental, transformation at scale (2003). The 'education 
epidemic' he imagines (Hargreaves, 2005) sees new ideas spreading contagiously because of their appeal and effectiveness - assessment for learning, pupil voice, thinking skills, and learning how to learn, might be examples of concepts with such possibilities but there is a danger that 'lift off' is deadened by the ways in which such concepts are spread. At best, in 'the dynamic knowledge economy', intellectual capital is mobilised through authentic processes of knowledge production and knowledge transfer. The social capital of the organisation and system has cultural and structural aspects reflecting the degree of trust which exists and the efficacy of the social networks which enables the self-motivated spread of innovation. Whilst TLRP's project user engagement and impact strategies might plausibly contribute to 'mobilising intellectual capital', the Programme has almost no influence on the social capital of UK education systems as a whole. Certainly, we have regular contact with, for example, DfES colleagues who manage the strategies workforce, but the mediating influences between research findings and practitioners in the field are very considerable. This is one reason why, as TLRP moves towards having better summaries of key findings, the infrastructures of other user bodies will be increasingly used to offer them in the public domain - the teacher associations, General Teaching Councils, subject associations and subject centres, professional newspapers, etc.

Major elements of the personalisation agenda to which TLRP has undoubtedly contributed are certainly being scaled up, but whether they will spread in a radical 'education epidemic' remains to be seen. History is rarely predictable, but TLRP will attempt to position itself and represent its findings so that any momentum in educational ideas can be exploited as it arises - whether by those who have been involved in the Programme or by those who will succeed them.

\section{Conclusion}

Underpinning this review of TLRP's strategies for transformation and impact, we might claim that TLRP has generated a significant number of innovative research findings, based in particular on the collective effort of users and researchers. Some of these certainly reinforce existing work, and are none the worse for that, but others clearly break new ground (see www.tlrp.org/findings).

We might also claim to have developed a range of channels and forms of communication which, we hope are appropriate for various audiences. The strategy of differentiating forms of output to meet specific user audiences involved a great deal of work and resource - and would not have been possible without the generous funding which TLRP has enjoyed. The use of task groups of researchers and users to produce Commentaries on contemporary issues appears to have been a particular success and it is exciting for the field that this strategy is now being taken up by others.

Engaging practitioners and policy-makers across the 'connecting web' was adopted as an goal, in principle, early in the Programme and was a significant commitment for many research project teams. Many were successful and some provide exemplary cases-studies of what can be achieved. Others were far less committed and, the impact of such projects tended to be less. Whilst mutual respect and clear communication seem to be absolutely necessary to unlock the 'connecting web', catching a moment of historical relevance is also a considerable help. It follows that time for contacts to develop, take up to occur and diffusion to take place is of crucial importance. Any relational impact strategy requires time for understanding and trust to grow, deepen and bear fruit. This is a major problem with the short term horizon of most researcher funding enterprises.

At this point, it is worth saying loud and clear though, that the infrastructural provision of a NICE in medicine or SCIE in social care is much needed in education. An 'evidence centre' 
was a key aspiration for the National Education Research Forum, when it existed, and the attempt to establish the Educational Evidence Portal (EEP) is a gesture in that direction being constructed at the limit of goodwill, technology and available funding. We have learned from TLRP that dissemination and impact work requires specialist expertise, technology, collaboration, imagination, commitment and, above all, time. The work is too important to be left to researchers alone, and too significant to be left to anything other than a fully independent body. To date, governments have not been sufficiently convinced of the need to resource such a knowledge centre in education - but in our open democratic societies, this must surely come some day?

I often characterise TLRP as a sort of 'adventure' - an initiative which started out facing somewhat unknown terrain which has been tackled with, I like to think, a certain amount of ingenuity and principled pragmatism. The Programme has enjoyed a great deal of support and good fortune and has benefited from strong alliances and partnerships. Yet whilst we certainly exercise agency, we do not make our own history, nor do we act in conditions of our own choosing. The eventual outcomes and influence of TLRP will only be known in ten years or so. By then, the Director's Team will have had opportunities to disseminate their synoptic analyses and the work of projects and thematic groups will have had time to ripple out through successive new phases of policy, practice and research activity.

In the meantime, TLRP will continue to struggle with its collaborative impact strategy attempting to be interactive, iterative, constructive, distributed and, hopefully, transformative.

\section{Acknowledgements}

I am grateful to the two referees, acting for the Cambridge Journal of Education, to Mary James, TLRP's Deputy Director, and to Martin Ince, a journalist who has shared his expertise with TLRP for some years, each of whom provided constructive comments on an earlier version of this paper. ESRC's C\&I ???? has been a constant source of support in bringing these thi

\section{References}

Cordingley, P. (2007) Transfer and Scaling Up, mimeo presentation to seminar, CUREE: Coventry

Edwards, A., Sebba, J. and Rickinson, M. (2007) 'Working with users: some implications for educational research'. British Educational Research Journal. Vol 33, No 5, pp 647-61.

Figgis, J., Zubrick, A., Butorac, A. and Alderson, A. (2000) 'Backtracking practice and policies to research', in The Impact of Educational Research, Canberra: Department of Education, Training and Youth Affairs

Hargreaves, D. H. (2003) 'From improvement to transformation', keynote lecture to the International Congress for School Effectiveness and Improvement, Sydney, Australia, January

Hargreaves, D. H. (2005) Education Epidemic, London: Demos 
Kanefsky, J. (2001) Maximising 'impact' - insights from research on the diffusion of innovations, mimeo, Exeter: TLRP

Martin, B., Molas-Gallart, J., Tang, P., Sinclair, T., Morrow, S. and Russell, V. (1999) Assessing Research Impact on Non-Academic Audiences, Progress report to ESRC, K604356029, Swindon: ESRC

Nutley, S., Walter, I. and Davies, H. (2002) 'From knowing to doing', Discussion Paper 1, Research Unit for Research Utilisation, St Andrews: University of St Andrews

Nutley, S.M., Walter, I. \& Davies, H. (2007) Using Evidence: How Research Can Inform Public Services (Bristol, The Policy Press).

Rogers, E. M. (1995) Diffusion of Innovations, New York: Free Press

TLRP (2001) ‘Communication and Impact Plan’, mimeo, Exeter: TLRP

TLRP (2002) ‘TLRP Output Review’, mimeo, Cambridge: TLRP 